\title{
A CAMPANHA PRESIDENCIAL TELEVISIVA DE LULA EM 2006 REVISTA DESDE A DIDÁTICA DA HISTÓRIA
}

\author{
Luis Fernando Cerri*
}

\section{Resumo}

Discute-se o papel da propaganda política televisiva no processo de ensino-aprendizagem de História, por meio dos processos de resgate e reforço de símbolos e ideias referentes à história política do Brasil, mobilizados para a construção de projetos de poder. Trata-se, portanto, de um estudo que pretende contribuir para o conhecimento das relações entre os aspectos formais e os aspectos não formais do ensino e aprendizagem da História. Parte-se do referencial teórico da Didática da História, que tem na consciência histórica o seu conceito principal (cf. J. Rüsen, K. Jeissman, P. Seixas e outros). A metodologia consiste, além dos instrumentais de análise das mensagens televisivas (sobretudo R. Barthes), na identificação e análise das narrativas e /ou "histórias ultracurtas" presentes no discurso político, capazes de ativar elementos do imaginário e da memória coletiva a serviço de fins imediatos. A conclusão preliminar é a circularidade entre o ensino - aprendizado escolar e as mensagens midiáticas, contribuindo para a compreensão da interdependência e jogos de dominação entre essas esferas.

Palavras-chave: Televisão. Propaganda Política. Consciência Histórica.

\section{LULA'S 2006 PRESIDENTIAL CAMPAIGN IN TELEVISION SAW FROM THE HISTORY DIDACTICS}

\begin{abstract}
The text deals with the role of political propaganda at television in the History teaching and learning process, through the processes of ransom and reinforcement of symbols and ideas referred to the Brazil's political history, targeted to the building of power projects. This is, therefore, a study that aims to contribute to the knowledge of relationship between formal and informal aspects of History teaching and learning. It begins by the theoretical basis of the History Didactics that gets on the historical consciousness its main concept (cf. J. Rüsen, K. Jeissman, P. Seixas and others). The methodology consists, beyond the tools of televising messages analysis (mainly R. Barthes), at the identification and analysis of the narratives and / or "ultra-short histories" that exists in the political speech that can activate elements of the imaginary and collective memory in immediate objectives' duty. The preliminary conclusion is that teaching-learning and media messages joins a same circle of relationship, and understand it is mean understanding the interdependence and domination games between these spheres.
\end{abstract}

Keywords: Television. Political propaganda. Historical consciousness.

\footnotetext{
* Doutor em Educação pela Universidade Estadual de Campinas. Professor da Universidade Estadual de Ponta Grossa. E-mail: lfcronos@yahoo.com.br
} 


\section{Introdução}

Os estudos de televisão compõem hoje um campo interdisciplinar para o qual concorrem a Antropologia, a História, a Sociologia, a Psicologia e assim por diante. Pretendemos nesse texto demonstrar a proficuidade da contribuição de mais uma disciplina, a Didática da História em sua configuração contemporânea, para as análises de textos televisivos que envolvem o tempo histórico em suas representações. Trata-se de uma via de mão dupla. Os estudos de televisão também são imprescindíveis para que a Didática da História compreenda a formação de ideias sobre a História que influenciam os processos formais de aprendizagem, assim como possa incorporar metodologias de análise, adaptandoas para uso escolar, como estratégia de preparação dos alunos para o consumo consciente de mídias. Desse modo, na interlocução com os estudos de mídia, previne-se o utilitarismo na incorporação de recursos audiovisuais na reflexão histórica na educação. Por essa perspectiva é promovido um olhar capaz de ultrapassar o âmbito estrito da metodologia de ensino, reduzida a métodos e técnicas, isolada da reflexão sobre o significado social e política de conteúdos, formas e procedimentos selecionados para incrementar o trabalho de sala de aula. Uma concepção utilitarista sobre o uso de recursos audiovisuais no ensino de História confunde inovação teórica e pedagógica com incorporação de novas linguagens e procedimentos.

O lugar epistemológico pelo qual dialogamos com estudos de televisão é o da reflexão didática sobre a história que constitui, segundo Klaus Bergmann, uma disciplina científica, a Didática da História, que “investiga sistematicamente os processos de ensino e aprendizagem de História, que são processos de formação de indivíduos, grupos e sociedades. (...) é uma disciplina que pesquisa a elaboração da História e sua recepção, que é a formação de uma consciência histórica.” (Bergmann, 1992, p. 30). Essa disciplina é constituída na fronteira entre a História e a Educação, e sua tarefa envolve, obrigatoriamente, a reflexão sobre os acontecimentos educativos não formais, incluindo a comunicação de massa. Qual seria, entretanto, o enfoque particular a desenvolver nesse campo das trajetórias não formais de ensino e aprendizagem? Defendemos que o enfoque é exatamente o da reflexão históricodidática, ou seja, a abordagem dos produtos da mídia com o olhar para os conteúdos referentes à temática da identidade no tempo, com as ferramentas da História, da Educação, da metodologia do ensino e de outros campos do conhecimento, preocupados com a formação da consciência histórica e a relação com o ensino escolar da história. 
A virada epistemológica da Didática da História, passando do como ensinar para incluir os fundamentos, objetivos, significado social, consequências individuais e coletivas, interações, significados do fenômeno social de ensinar e aprender conteúdos históricos (Rüsen: 2001; Laville: 2004) ainda está em curso. O momento é de identificação dos campos de investigação e desenvolvimento de estudos preliminares que têm uma dupla finalidade: lançar luzes sobre os objetos em si, bem como adaptar, experimentar e desenvolver metodologias para sua abordagem dentro da reflexão didática. Esse texto vai nesse sentido, ao abordar um tema que não é comumente identificado como objeto da Didática da História. Apostamos que essa é uma nova fronteira da pesquisa educacional, sobretudo, na contramão da opinião de que esse campo se restringe à escola e à sala de aula; os que assim pensam correm o risco de, restringindo o olhar à especificidade, perder a capacidade de compreender suas razões gerais juntamente com a capacidade de intervenção consistente.

A reflexão proposta comporta dois movimentos:

- o estudo da formação de saberes e quereres prévios e paralelos ao ensino de história, o condicionamento que proporcionam para o ensino de história;

- a produção de elementos para responder a como (e por quê / para que) utilizar a televisão em sala de aula, movimento pelo qual a metodologia do ensino beneficia-se de uma postura não utilitarista e de uma visão ampla do processo, ou seja, que não o reduz à técnica, nem ignora a unidade entre meio e mensagem. Dentro desse movimento, é útil reconhecer que o avanço nas tecnologias de informação e comunicação, notadamente da Rede Mundial de Computadores, mudaram a relação das pessoas com os produtos da televisão. Com a Internet, alunos e professores podem ter acesso a programas de televisão já exibidos, acessando-os da forma e nos horários que julgam mais interessantes. Na rede, existem diversos sítios com conteúdos de televisão de diversos países, regiões de um mesmo país ou mesmo de outros tempos: é até possível alguma arqueologia televisiva, já que é possível encontrar programas e peças publicitárias do início das transmissões televisivas, bem como trechos de filmes e cinejornais. Após o surgimento do Youtube, a tecnologia de transmissão de vídeos pela linguagem Flash não só permitiu a ampliação de sítios do gênero como incentivou a alocação de vídeos em diversos tipos de portais na rede mundial de computadores. Embora arquivos de vídeo há muito estivessem disponíveis na rede, a tecnologia flash, combinada com conexões de banda larga, permitiu que estes fossem vistos sem a necessidade de baixá-los, aproximando-se da experiência televisiva; a grande diferença em relação a esta é a possibilidade do usuário baixar, gravar, editar e subir vídeos para a rede, estabelecendo uma via de comunicação de mão dupla. 
Precisamos ter em mente que a revolução informacional pela qual passamos está mudando a relação de audiência - sobretudo dos mais jovens - com a mídia. A relação entre internet e televisão está mudando algumas caracterizações clássicas desta. A ideia de que a experiência televisiva é um fluxo contínuo marcado por pontuações (principalmente comerciais) fica relativizada quando as pessoas começam a assistir apenas o que lhes interessa, diretamente da rede mundial de computadores. Outro fator dessa mudança é a contínua expansão da banda larga e, na América Latina, a disseminação das Lan Houses, inclusive em espaços de periferia urbana (Belintane: 2006) para crianças e jovens marginalizados, o que anula o argumento de que não é preciso que o professor da escola pública se dedique a esse tema e a essa competência, já que seus alunos não teriam condições de acesso à Internet. Outro aspecto que não se pode desconsiderar é que a emergência da rede como meio de comunicação interpessoal e bilateral altera a forma de consumir televisão, ocasionando o fenômeno do declínio da audiência das grandes redes e a crise das estruturas voltadas à criação de conteúdos pensados para uma massa indistinta de pessoas. O desafio da televisão é a fragmentação da audiência e o atendimento às necessidades de interação crescentes do público. O próximo passo é a efetiva adesão dos consumidores de países em desenvolvimento aos aparelhos para uso do sistema de televisão digital, capaz de integrar as características da televisão com as do computador e da Internet, rompendo definitivamente as fronteiras para uma presença massiva na Internet.

Obviamente, esse quadro impõe mudanças para as práticas educativas e mescla a educação promovida pelos meios com a educação fornecida pela escola, retirando-lhe em definitivo seu caráter de instituição fornecedora de ideias e informações. Quanto da crise educacional na atualidade se deve à insistência de formuladores de políticas (e definidores de orçamentos), professores e gestores em manter esse caráter transmissivo para a educação escolar?

Outro elemento de contexto para justificar a escolha temática desenvolvida e somar elementos para propostas de ensino integradoras de forma e conteúdo, de aspectos externos e internos à escola, é a conjuntura de um governo liderado por um partido de esquerda, o Partido dos Trabalhadores, cabendo aos militantes e simpatizantes parte substancial da crítica social, política, acadêmica e educacional no Brasil dos anos 80 e 90. No governo federal desde 2003, a frente de uma coligação de forças políticas que limita ou impede a implementação de muitas de suas propostas e posturas originais, os conteúdos produzidos pelo PT e pelo governo federal dirigido por Lula oferecem um rico corpo documental para o exercício de remodulação do pensamento e procedimento crítico, após a chegada de uma 
geração de críticos ao poder ter redefinido o discurso oficial e as formas pelas quais ele elabora e usa conteúdos históricos.

Trata-se de pensar e fazer a contribuição da História para a alfabetização para os meios de comunicação de massa, o que só se viabiliza na reflexão histórico-didática (vide, por exemplo, Cerri, 1999; 2005; 2006).

\section{Representação política e representação identitária}

Nesse tópico, desenvolveremos uma análise inicial e provisória sobre a propaganda política eleitoral na campanha do presidente Lula à reeleição, em 2006, com especial atenção para os aspectos da didatização de ideias, recurso a conteúdos históricos mais ou menos evidentes e produção de identificações entre governante, nação e povo.

Em termos de experiência televisiva, de percepção da audiência, as campanhas políticas podem ser comparadas à experiência dos blocos de propaganda comercial convencional, ou seja, são recebidas com desconforto e ansiedade pela volta da programação normal. No Brasil, as redes televisivas são obrigadas a transmitir gratuitamente a propaganda eleitoral em blocos de 50 minutos à tarde e à noite (divididos entre os partidos) e inserções partidárias em spots durante toda a programação, também divididos proporcionalmente entre partidos ou coligações, sempre de acordo com sua representatividade no Congresso Nacional.

Partimos do princípio de que a campanha política vitoriosa não é aquela que manipula um povo maleável e dócil à propaganda - o que, aliás, é uma leitura unívoca e simplista - mas aquela que consegue interpretar e representar as características do ter sido (memória), do ser (convivência cotidiana no presente) e do continuar sendo (projetos pessoais e projetos de nação, ou comunidade de destino, nos termos de Otto Bauer) da maioria do povo brasileiro, aqui recortado em seus milhões de eleitores. Evidentemente, a definição dessa identidade varia no tempo, e sofre também a influência do esforço de propaganda das diferentes forças políticas, o que estabelece uma relação dinâmica entre propaganda e opinião pública, que se determinam mutuamente e sofrem os condicionamentos de outros itens como as condições materiais, flutuações econômicas, evocação ou esquecimento de imagens e ideias historicamente sedimentadas e disponíveis no “capital pensante da humanidade”, como B. Baczko denomina o imaginário.

Os primeiros estudiosos do fenômeno cuidaram de diferenciar propaganda (voltada para a divulgação e o convencimento das pessoas quanto a princípios e ideias gerais, sobretudo políticas) e publicidade (voltada para a difusão de produtos e marcas e a convencer 
para o consumo). Muito cedo, entretanto, percebeu-se que essa fronteira era difusa e que a propaganda política era pródiga no uso de elementos de publicidade: o clássico “A propaganda política”, de Jean-Marie Domenach, o indica desde os anos 50. Por isso, a compreensão das campanhas políticas contemporâneas deve considerar esse aspecto, de modo a evitar certo moralismo improdutivo, e compreender que, de fato, na sociedade de consumo de massa, o eleitorado espera e deseja que o seu candidato se comporte como "sabão em pó,” e preza, em proporções variáveis, a “embalagem” e o “conteúdo” do candidato e do projeto que "compra” ao digitar seu voto na urna. Admitir isso é um passo importante e útil no sentido de contribuir para a promoção do ideal de que a discussão política seja mais realista, efetiva e aprofundada; mais ainda, é admitir que será útil, sobretudo se resultar em propostas educativas que colaborem para que eleitores e futuros eleitores identifiquem os aspectos “publicitários” no debate político, sobrepujem-nos e, de preferência, sejam capazes de produzir propagandas e debates que, sem prejuízo de princípios, sejam suficientemente pragmáticos. Ou seja, desconstruir a publicidade do "sabão em pó” político é um ensaio de aprofundamento da democracia e de incremento da cidadania dos participantes, que começa quando se conhecem as regras do jogo como elas são, renunciando a navegar no espesso caldo das projeções de como elas deveriam ser.

Ao trabalhar com os programas televisivos como fonte para o tipo de reflexão / pesquisa educacional, desenvolvida nesse texto, é preciso considerar as limitações e possibilidades do poder da mensagem televisiva. Baptistella exemplifica uma tendência importante nos estudos de televisão ao apontar que um dimensionamento realista do papel dessa mídia leva em conta que os telespectadores não aceitam de modo passivo todas as mensagens televisivas. Pelo contrário, ver televisão é um aprendizado, e é enganoso pensar segundo o estereótipo de que o efeito da televisão é incutir atitudes e opiniões nos telespectadores, ou compor um modelo de realidade para que pouco pensem ou resistam às ideologias transmitidas (Baptistella, 2001, p. 110).

Por outro lado, se a mensagem televisiva não tivesse efeito sensível sobre as pessoas, não faria circular bilhões em publicidade, nem teria se convertido numa indústria tão poderosa. Estudos iniciais sobre efeitos da propaganda política apontavam pouca importância sobre os eleitores e suas decisões finais, mas os estudos mais recentes mostram uma influência forte e crescente (WEST, 1995, p. 790), fenômeno que pode tanto refletir a melhoria dos instrumentos de pesquisa quanto o desenvolvimento da utilização e a criação de novas ferramentas do marketing político. Os elementos do imaginário empregados pelos publicitários (e mesmo roteiristas de novelas ou reality-shows) resultam de avaliações do 
público e rigorosas pesquisas qualitativas, visando os objetivos estabelecidos, seja em nível de audiência, seja em consumo dos produtos anunciados. Demonstrativo dessa capacidade de governar o fluxo interativo entre a mensagem publicitária e opinião pública é o sucesso da campanha política de Lula em 2006, com a reversão da influência das denúncias do “mensalão” e, durante a campanha, da denúncia dos milhares de reais encontrados pela Polícia Federal com pessoas envolvidas na campanha Lula, para supostamente comprar um dossiê contra os adversários, no que ficou conhecido como o caso dos “aloprados”. De uma tendência a empate no início do segundo turno, a campanha seguiu para um distanciamento crescente da candidatura de Lula na liderança das pesquisas de opinião. As mensagens da estratégia de propaganda da campanha Lula tiveram influência importante nas atitudes políticas do eleitorado, ou, em outras palavras, conseguiram associar-se a imagens validadas positivamente pela maioria do povo, imagens essas aprendidas numa multiplicidade de espaços e meios, inclusive o ensino de história e o livro didático. Dito assim de forma crua, pode parecer que o cálculo político do eleitor não tem significado algum, o que não é correto, mas esse cálculo é apenas parte do processo que leva até o voto, uma vez que uma campanha é a arte de manter consigo os que optaram pelo projeto desde o início, ganhando espaço entre os indecisos e entre os que haviam decidido votar em outros candidatos. O sucesso desse trabalho pode, inclusive, influenciar o cálculo político que alguém havia feito inicialmente, alterando-o.

De acordo com Rüsen (2001), a narrativa é a expressão empírica da consciência histórica; por meio dela, o sentido e o significado do tempo produzidos encontram uma forma de expressão e um papel na convivência humana. O autor refere-se às narrativas não ficcionais, que podem partilhar os recursos lógicos e estéticos com as ficcionais, mas não se confundem com elas. Além de terem realmente acontecido, parte-se do pressuposto que os eventos narrados e as próprias narrativas referem-se a elementos que influenciam concretamente a vida prática dos que a partilham. Mesmo que não se refira ao nosso recorte temporal ou espacial mais próximo, as narrativas de caráter histórico nos mobilizam de algum modo, seja pela identificação a sujeitos, seja pela reflexão sobre como nos comportaríamos naquele caso e, portanto, exercitamos nossa identidade, nosso pertencimento a tal ou qual grupo ou tipo de pessoas.

A televisão, por sua vez, é um repertório de narrativas. Para Burton, essas narrativas sequências de figuras e 'histórias' - se impõem independentemente do princípio narrativo; pode ser documentário, noticiário ou drama: a estrutura narrativa está sempre presente (BURTON, 2000, p. 8). As campanhas eleitorais televisivas são o espaço das narrativas cuja 
“moral da história” é composta pelas interpretações que se busca dar aos acontecimentos políticos que estão em julgamento, para outras narrativas que concorrem com maior ou menor intensidade - em forma verbal, de imagens ou símbolos - que jogam sua carga sobre um julgamento do presente com elementos do passado.

Um último comentário prévio refere-se ao papel dos anúncios políticos no que tange ao crescente apelo a aspectos emocionais. Segundo West,

Citizens form a variety of impressions during the course of election campaigns, from views about candidate issue positions and personal characteristics to feelings about the campaign prospects of specific candidates. As ads have become more gripping emotionally, affective models dealing with feelings and emotions have been seen as crucial to candidate fortunes. (WEST, p. 791-2, 1995)

A questão que se coloca aqui é que tipo de emoção a propaganda de Lula manipula, e de que maneiras. Procuraremos promover a seguir uma leitura textual dessa fonte, concentrando a atenção nas mensagens emitidas, sem desconsiderar o dado da recepção e da leitura por parte da audiência, exatamente porque nos interessamos por elementos de cultura histórica e política preexistentes no eleitorado brasileiro, além de considerar também as predisposições dos eleitores. Não poderia ser diferente, pois é o diálogo constante com as impressões do eleitor que produz e altera o rumo das campanhas, como destaca Fuenzalida:

Por mucho tiempo se ha creído que la audiencia sería una receptora pasiva de los signos televisivos. Pero no es así: la audiencia ha ido aprendiendo acerca del medio a través de su experiencia, de conversaciones y lecturas, y por ello sabe cada vez más acerca de la televisión, ha aprendido ha discriminar activamente la información que le parece creíble y tiene gustos sobre programas entretenidos o aburridos. La idea de ciertos políticos en el pasado era que bastaba aparecer en $\mathrm{T} \mathrm{V}$, esto es, adquirir visibilidad, para ser automáticamente valorado como elegible. Pe ro muchos cambios en la concepción ciudadana acerca de qué atributos constituyen un político capaz muestran que la audiencia distingue crecientemente la visibilidad televisiva de los políticos de su capacidad. (FUENZALIDA, 2004, p. 54)

\section{História nos programas eleitorais de Lula em 2006}

A análise das peças publicitárias e dos elementos de história e orientação histórica que mobilizam para a consecução de seus objetivos tem que ser entendida dentro do contexto em que são vistas. No caso da televisão, é necessário imaginar que assistir a uma propaganda eleitoral se insere em um continuum, marcado pelo ato em si de ver TV, o que insere a 
campanha no contexto de outros programas eleitorais e todos eles no contexto da programação televisiva e da atitude geral que se assume ao assistir TV. Trata-se do gesto envolvido na recepção das mensagens publicitárias, que implica “manter-se na superfície da imagem sem distinguir fundamentalmente seus conteúdos” (BARTHES, 1994, p. 508). A natureza deste gesto facilita o estabelecimento de uma relação imediata entre a publicidade e o imaginário social, que envolve saberes e imagens de identidade coletiva no tempo.

Até 2002, as campanhas presidenciais do Partido dos Trabalhadores passavam uma imagem dura, agressiva, crítica, associada frequentemente às passeatas e bandeiras vermelhas do PT e partidos socialistas aliados. O candidato era representado como um líder convicto e sério, capaz de arrancar palavras de ordem e punhos fechados socando o ar, das multidões que se reuniam nas atividades sindicais e partidárias. A expressão facial dura, herdada das lutas sindicais, sob as difíceis condições políticas em uma ditadura, aparecia como marca registrada do candidato. Dirigia-se e representava, portanto, uma parcela organizada da sociedade, reivindicadora, mobilizada, politizada, mas ainda assim, apenas uma parcela.

Em 2002, a campanha Lula foi dirigida pelo publicitário Duda Mendonça, conhecido pela sua capacidade de "virar o jogo" carregando à vitória candidatos de direita que pareciam estar fora do páreo. Lula torna-se o "Lula light” ou o "Lulinha paz e amor”, evitando fazer denúncias bombásticas, atacar os adversários, e preferindo comportar-se como um grande pai e conciliador. A serenidade e o sorriso passam a dominar seu rosto. Com isso, Lula e o PT passam a sinalizar a intenção de representar a identidade nacional, representar o todo, e não uma parcela. Essa atitude aponta como a equipe publicitária entendia a autorrepresentação do brasileiro, naquele momento avesso ao confronto. Logicamente, a estratégia não foi bem sucedida por si só, mas pelo contexto de crise e sensação de esgotamento das saídas neoliberais dos mandatos de Fernando Henrique Cardoso e pela sinalização clara de que Lula seria o oposto perfeito ao então presidente ${ }^{1}$.

Em 2006, a identidade nacional que o programa quer personalizar em Lula reforça a perspectiva popular, de baixo para cima, aproveitando as vertentes do pensamento nacional orgulhosas da mestiçagem do povo (formadas por intelectuais como Gilberto Freyre e Darcy Ribeiro), e do carisma de Lula. É o momento de explorar a imagem de Lula como símbolo do Brasil que se quer, um país em que um retirante que passou fome e um operário que marcou presença no sindicalismo pode ser presidente, mesmo sem diploma universitário. É a negação da imagem elitista do Partido da Social Democracia Brasileira, de FHC o qual por sua vez era

\footnotetext{
1 Vide análise desenvolvida pelo professor Antonio Albino Canelas Rubim em: <http://egroups.unb.br/fac/comunicacaoepolitica/Albino.pdf $>$.
} 
dado a desfazer do Brasil e dos brasileiros em algumas declarações, priorizando a "modernidade" acima do bem estar das pessoas, o que passou também uma imagem de insensibilidade social e negação dos valores identitários que se constituíram no início do século XX como uma alternativa de viabilização de um projeto nacional conciliador de elites e povo ${ }^{2}$. Além disso, trata-se de articular a condição popular de Lula com a sua pretendida superioridade como governante. Entra em cena aí um uso da narrativa histórica que associa a trajetória de Lula a milhões de migrantes pobres, no processo do êxodo rural, bem como o associa, por sua história pessoal, às qualidades de um bom presidente (fig. 1) ${ }^{3}$. Assim, Lula encarna o povo brasileiro, nos dizeres de seu jingle de campanha:

"São milhões de Lulas povoando esse Brasil

Homens e mulheres noite e dia a lutar

Por um Brasil justo e independente

Onde o presidente é povo e o povo é presidente”

No reforço da identificação de Lula com as classes populares, recorre-se ao arquivo pessoal do presidente e são exibidas fotos pessoais do período da infância, formação técnica, ação sindical, sempre contrapondo a fotos de Lula em situações de estadista, como na ONU, com George Bush ou a rainha da Inglaterra, mas também ao lado do povo simples, expondo o político como interlocutor preferencial das classes populares com o Estado. As imagens das lutas sindicais e de multidões com Lula em assembleia cumprem, por sua vez, o papel de diferenciar Lula dos líderes populistas a cujo período o imaginário “desenvolvimentista” faz menção, afastando a insinuação de uma liderança messiânica, paternalista ou populista, pontos que foram básicos na origem do "Novo Sindicalismo”, que por sua vez está na base do petismo.

\footnotetext{
${ }^{2}$ Segundo Renato Ortiz na obra Cultura brasileira e identidade nacional (1985), a positivação da mestiçagem e de alguns valores afro-brasileiros e indígenas foi uma operação intelectual conduzida entre as décadas de 1910 e 1940, que permitiu a construção de projetos nacionais capazes de envolver, pelo menos no imaginário, toda a nação, e não só uma elite, como ocorria com as teorias eugenistas e as políticas de branqueamento levadas a efeito na Primeira República. As marcas do passado escravista, entretanto, mais profundas, continuaram a produzir um racismo arraigado no cotidiano, bloqueando ou dificultando fortemente a ascensão social de negros, índios e mestiços, e condicionando os raros casos de ascensão a assimilação dos padrões culturais e sociais da elite branca.

${ }^{3} \mathrm{O}$ vídeo completo está disponível em: <http://www.youtube.com/watch?v=jgIzwkgMKjA>.
} 


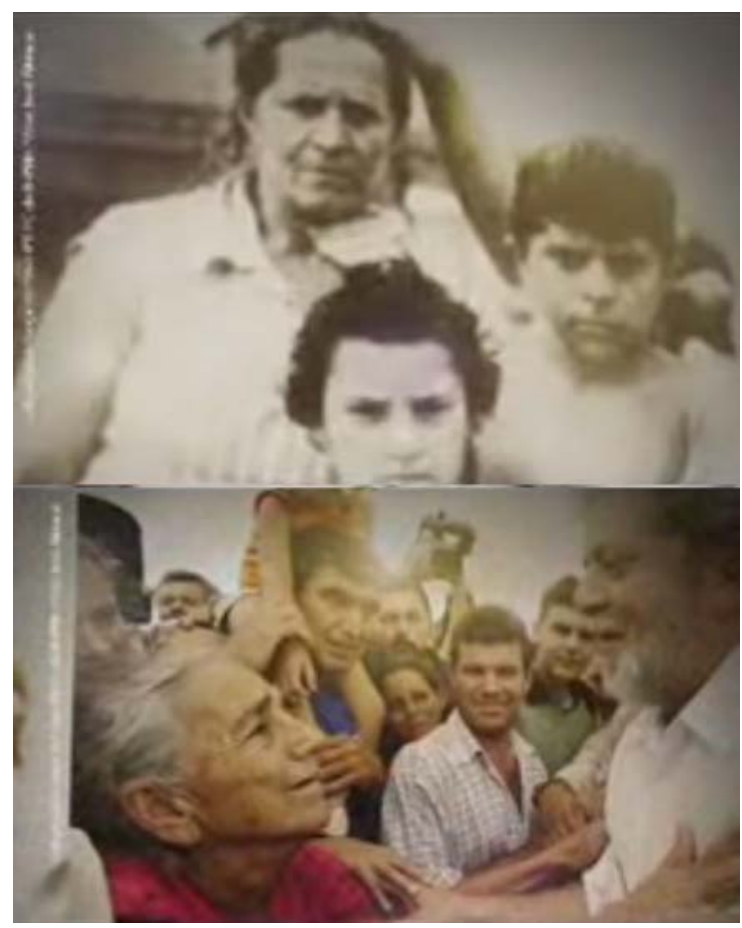

Figura 1 - Captura de imagens do programa de Lula de 15 de Agosto de 2006 - Ao fundo o locutor diz: "O Lula que trabalhava como engraxate para ajudar a colocar comida na mesa de sua casa, e hoje ajuda a colocar comida na mesa de 45 milhões de brasileiros".

Em 2002, além de sorridente, Lula aparecia trajando ternos bem alinhados, para relativizar a imagem popular e favorecer também a imagem de dirigente capaz e estadista renomado. Em 2006, ao discutir temas da agenda governamental na propaganda televisiva, Lula está bem composto, cabelo e barba aparados e alinhados, camisas impecavelmente passadas. Nas situações de contato direto com o povo, é retratado em desalinho, rosto e cabelos empapados de suor, roupas amarrotadas, mas extremamente feliz e sintonizado com as pessoas, que o acolhem carinhosamente, com bastante contato físico, típico de grande parte dos padrões de intimidade na cultura nacional. É a expressão em imagem do carisma político num viés popular brasileiro: Lula aparece convincentemente à vontade, porque está "entre os seus”. Ao contrário, o adversário Geraldo Alckmin (governador de São Paulo e líder da ala direita do PSDB paulista) no meio do povo, embora sorridente, é comedido e até um pouco frio ou desconfortável, e permanece arrumado como se estivesse no estúdio. A foto de Lula sendo tocado no rosto por um menino negro, utilizada na abertura e no cenário dos programas eleitorais (figura 2), é uma espécie de símbolo dessa unidade entre presidente e povo, aí representado por aqueles populares da foto. Essas são algumas das tantas imagens que opõem os candidatos rivais e alinham Lula e seus eleitores como a figura privilegiada na imaginação da nação. Para Ramaldes e Reis (2006), a propaganda funciona no sentido de estabelecer Lula 
não como um representante do povo, mas como a síntese do povo, numa ligação orgânica e indivisível.

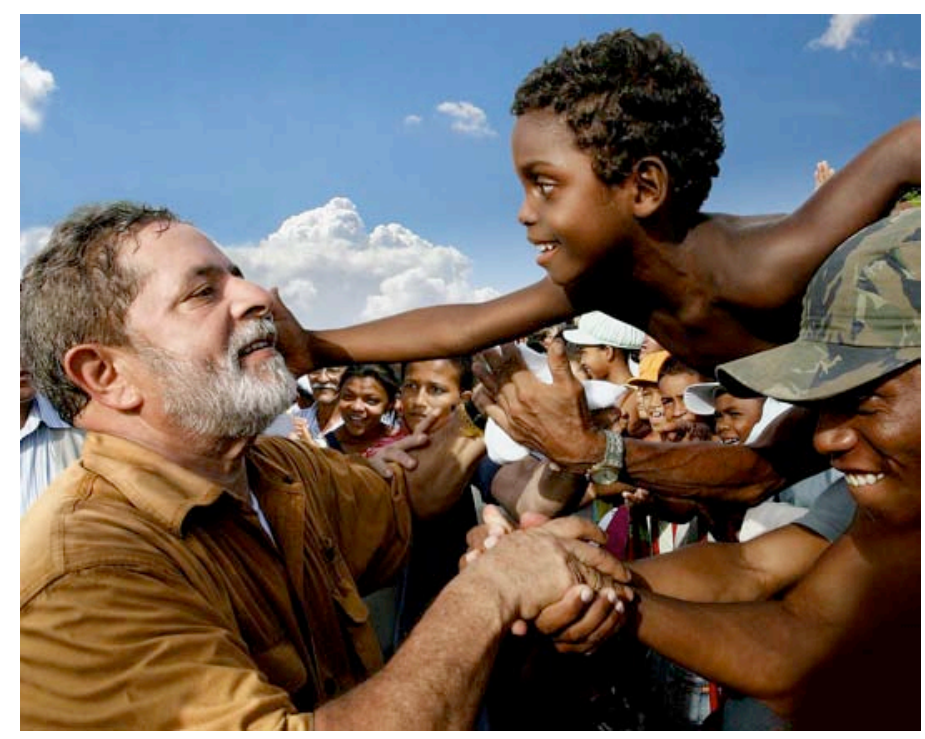

Figura 2 - Foto de Ricardo Stuckert/PR

Evidentemente, foi confortável para a equipe publicitária contar com a situação de o candidato ser - não só no discurso, mas na aparência (incluindo um dedo amputado por causa de um acidente de trabalho) - um filho do povo, em um governo popular, mas isso foi colheita de um imaginário trabalhado por muito tempo, durante o qual a ideia parecia intolerável, o que foi usado pelos adversários sem restrições, em contextos em que a baixa autoestima popular colava-se à imagem do petista. Foi necessária mais de uma década de insistência propagandística, e um momento político favorável à tese, para que o povo assumisse a possibilidade de uma pessoa vinda de baixo, um "não doutor” na sociedade do "você sabe quem está falando" ${ }^{4}$, ser presidente do Brasil. Com esse histórico pessoal não é difícil marcar-se como parte do povo, como seu representante legítimo, coisa que a propaganda de Alckmin não conseguiu senão com grande artificialidade e falta de jeito.

A questão que se pode interpor aqui é que essa forma de comunicação, de caráter visual-afetivo, entraria em choque com o caráter racional e verbal que a disputa política e a escolha eleitoral deveriam ter. Ao analisar as campanhas eleitorais chilenas, Fuenzalida (2004) aponta que a distinção entre uma forma afetiva/ visual e uma forma racional/ verbal, que lograriam respectivamente a sedução e o convencimento do eleitor, na verdade é uma posição pré-televisiva. Para ele, a relação problemática da política com a sedução é inerente a

\footnotetext{
4 Sobre essa famosa frase, reveladora de um padrão das relações sociais brasileiras, leia-se "Carnavais, Malandros e Heróis”, do antropólogo Roberto da Matta, em especial o capítulo IV - "Sabe com quem está falando? Um ensaio sobre a distinção entre indivíduo e pessoa no Brasil”.
} 
este tipo de atividade humana, pois a política pré-televisiva também se valia de uma formulação estética, nesse caso retórica, talvez pouco distinguível dos argumentos racionais por sua condição de discurso verbal. Em consonância com esta postura, defendemos que, para o eleitor, a sedução midiática não é necessariamente incompatível com o cálculo racional. Pelo contrário, é preciso que a estética televisiva integre-se ao cálculo político do eleitor.

Em 2006, a campanha Lula beneficiou-se de representar também o poder de Estado, sendo pela primeira vez a candidatura de situação. Nessa condição, tem sido natural para os governantes “metonimizar-se” como o próprio Brasil, recurso discursivo implícito usado frequentemente, inclusive contra Lula em 1994, quando se dizia que, por ser contra o Plano Real de estabilização econômica (por ser opositor de Fernando Henrique, então candidato da situação), Lula era “contra o Brasil”. Se a palavra - chave da era FHC era “modernidade”, a da era Lula é “desenvolvimento”. Para a elaboração das peças publicitárias, portanto, as imagens buscadas são aquelas exploradas em períodos que evocaram uma mensagem parecida, o período do pós-guerra e o período do "milagre econômico", durante a ditadura militar. Trata-se, de uma releitura nacionalista, que se sustenta em lutas de mais de meio século por soberania nacional, da nacionalização do petróleo, por exemplo, (principalmente a campanha “O petróleo é nosso” durante o governo de Getúlio Vargas nos anos 50). Essa remissão se concretiza numa outra imagem da abertura do programa eleitoral na televisão, que é o presidente Lula em trajes de proteção individual, com as mãos ensopadas de petróleo, em uma plataforma da Petrobrás (fig. 3).

Verifica-se, portanto, a necessidade de recorrer a um imaginário cultivado no populismo dos anos 50 e 60, e mesmo a elementos do nacionalismo da propaganda da ditadura militar ${ }^{5}$. A didatização dessas ideias passa por recursos semelhantes aos utilizados nas décadas anteriores, como a representação cartográfica como recurso de imaginação da nação, sendo saqueada por uma mão que retira empresas públicas e passa sua sombra ameaçadora sobre as empresas que restaram sem privatizar. A imagem do inimigo oculto, com toda a sua força política, é reforçada com os dizeres ao final desse comercial de 30 segundos, com dizeres que separam o adversário político (“eles”) da nação (o espaço privilegiado do “nós” - dito com a palavra “povo” - fig. 3). O dado de realidade que vincula a representação ao real para afastá-la da ficção é o nome das empresas que foram efetivamente

\footnotetext{
${ }^{5}$ É importante relembrar que o programa de fundação do PT surge na oposição, tanto à ditadura militar quanto ao trabalhismo varguista, cuja herança na estrutura sindical foi preciso ultrapassar para construir o "novo sindicalismo” no qual Lula e seus companheiros se destacaram, e que confluiu para a criação do PT.
} 
privatizadas durante o mandato de FHC, e das que o candidato Alckmin privatizou enquanto foi governador de São Paulo.

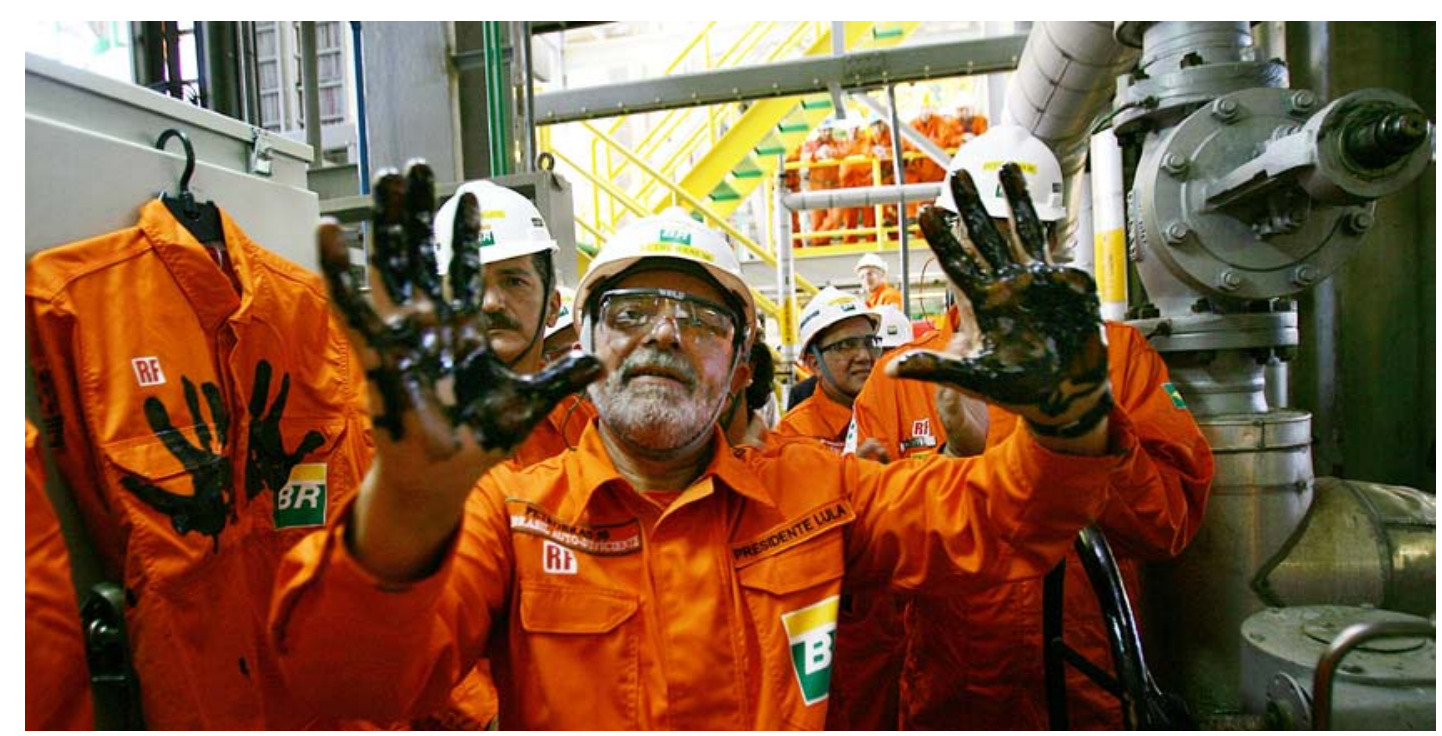

Figura 3 - Créditos: Secretaria de Imprensa da Presidência da República do Brasil. (http://www.imprensa.planalto.gov.br)

No grande tema da campanha, o nacionalismo e a valorização nacionalista do povo, da terra e do estado nacional (e sua soberania, representada no território e nas empresas), trata-se de reinventar e reescrever o otimismo secular que ciclicamente se refaz depois de fases de retração e baixa autoestima (sobre essa tradição nacional, ver Fico: 1997). Em 2006, por exemplo, recorre-se e reivindica-se a história de Santos Dumont e o pioneirismo do primeiro voo de um aparelho mais pesado que o ar, o 14 bis, para associar com o pioneirismo brasileiro da alternativa energética dos biocombustíveis. Alguns meses antes da campanha eleitoral, o governo brasileiro empenhou-se na comemoração do centenário do voo do 14 Bis com o envio do primeiro astronauta brasileiro ao espaço, para a estação espacial internacional, em uma nave russa. Para muitos, o interesse científico e de colaboração tecnológica para a participação do Brasil nas atividades espaciais foi nulo, e o lançamento teve mais caráter simbólico (uma marca, na memória coletiva, para os 100 anos do voo do 14 bis) e político (uma iniciativa de incentivo ao nacionalismo para angariar apoio popular ao governo).

O apelo ao nacionalismo ficará mais claro no segundo turno das eleições presidenciais. Uma denúncia de compra de um dossiê contra o PSDB, por parte de petistas, com uma montanha de notas de dinheiro (fotografada e passada em primeira mão por um delegado da Polícia Federal à Rede Globo) deu sobrevida ao candidato tucano. A reação da campanha de Lula foi vigorosa e bem sucedida: associar, por meio de spots, o PSDB à privatização das empresas públicas brasileiras, utilizando um mapa do Brasil com maquetes simplificadas 
representando as empresas vendidas. Essas maquetes eram retiradas do mapa do Brasil por uma mão cujo dono sumia no escuro, indicando que tais vendas não tinham sido feitas às claras e haviam beneficiado interesses ocultos do público (fig. 4) ${ }^{6}$. Numa inversão do discurso neoliberal, as empresas “do governo" passam a ser reconhecidas como "empresas do povo” e que, portanto, não devem ser vendidas, e muito menos no tipo de transação obscura que a imagem sugere.

Embora não possa ser vista como único fator, essa campanha estancou a subida de Alckmin e permitiu a retomada dos patamares anteriores de Lula, que pôde vencer a eleição por uma margem confortável. Mais que isso, simbolicamente o sucesso desses spots indicam o esgotamento da parte do discurso neoliberal que consiste em localizar no Estado e nas empresas públicas (instrumentos de intervenção daquele) quase todos os males dos quais padeceriam a sociedade, a economia e a política. O que entra em crise é a proposição do Estado mínimo, que não terá nenhuma força no segundo mandato de Lula.

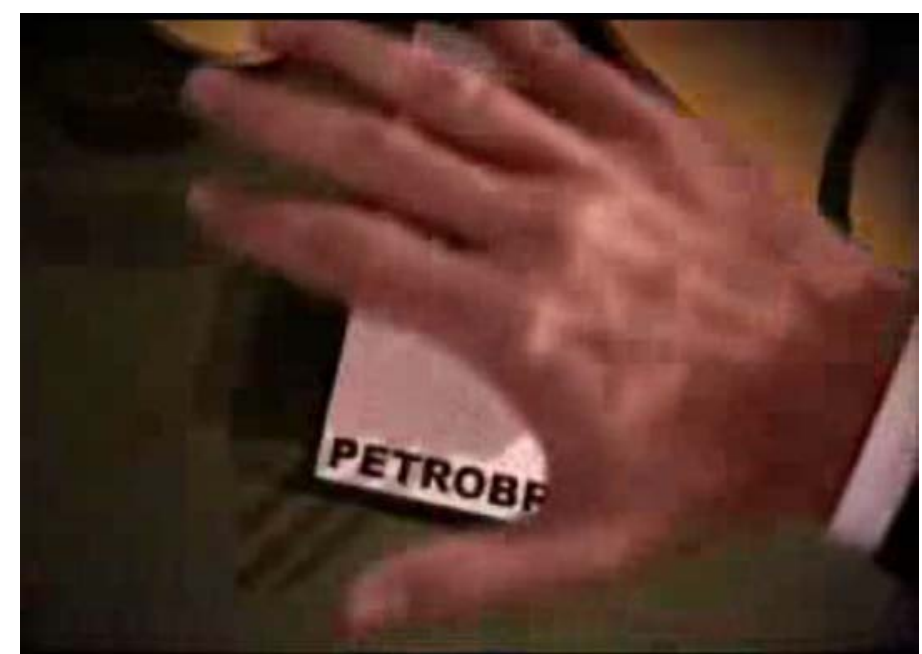

Figura 4 - Captura de imagem do programa eleitoral de Lula 2006 (2o. Turno)

A representação do povo brasileiro é desenhada por meio dos apresentadores do programa: são sempre três, e embora variem ao longo da campanha, sempre envolvem uma pessoa branca, uma negra, uma índia, e sempre há uma mulher entre eles (fig. 5). O recurso histórico aí empregado é o "mito das três raças" pelo qual tradicionalmente explica-se a formação do povo brasileiro. Embora ela tenha sido questionada e posta em xeque há cerca de 50 anos $^{7}$, essa representação aparece firme na consciência histórica do povo brasileiro,

\footnotetext{
${ }^{6} \mathrm{O}$ vídeo completo está disponível em http://www.youtube.com/watch?v=IEXTi-aVkJE.

${ }^{7}$ Um dos principais questionadores dessa explicação é o sociólogo e fundador do PT, Florestan Fernandes: em suma, o Brasil não resulta da integração das três raças, mas da criação de um mundo que serve ao branco, para o
} 
capturada pelo planejamento publicitário da campanha Lula. Além disso, segue praticamente invicta no ensino escolar da história e das demais disciplinas no campo das humanidades. Considerando as iniciativas do governo Lula para benefício das populações negras e indígenas, um país formado por esses três grandes troncos étnicos, em função do interesse dos brancos, se constitui agora como projeto: uma sociedade em que as raças convivem e colaboram em um mesmo projeto nacional é uma indicação de futuro, uma promessa, e a construção de uma comunidade de destino.

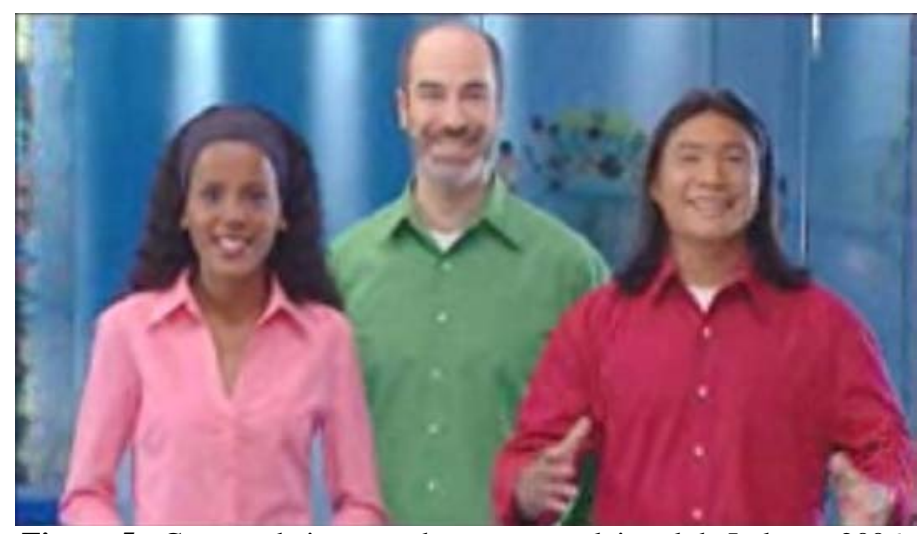

Figura 5 - Captura de imagem do programa eleitoral de Lula em 2006.

Em termos de promessas, a campanha Lula expressa o âmago das perspectivas do projeto político petista no poder, um projeto pragmático e que adia indefinidamente as medidas para criar condições na passagem ao socialismo, conforme o programa partidário. Pelo contrário, a imaginação oferecida para o futuro é realizar aquilo que a burguesia nacional não conseguiu (ou não quis) executar, o Brasil como nação (cujo conceito não aceita a exclusão do elemento solidariedade e corresponsabilidade entre os membros). Em outros termos, trata-se da promessa social-democrata original de capitalismo para todos (comida, consumo, propriedade), como face do horizonte utópico do governo Lula. O sindicalista, o socialista, o líder de um dos maiores partidos de esquerda do continente, finalmente está no poder, mas para isso o projeto foi alterado. A campanha política é um indicador do projeto político efetivamente implementado, e suas razões ou desculpas. Sobretudo, é um programa tranquilizador, pacificador - não se trata de mobilizar para a luta, para o combate, para a derrota do inimigo e para a tomada do poder. Por isso os elementos do imaginário radical (as bandeiras vermelhas, as palavras de ordem) são minimizados e as imagens tranquilizadoras são destacadas.

qual negros e índios são coagidos a construir, e do qual não tomam parte senão negando a si próprios (Fernandes: 1971). 


\section{Em suma}

2006 pode ser considerado um ano político atípico para o Brasil. Em 2002, os desgastes acumulados do governo de Fernando Henrique Cardoso indicavam desde cedo que a vitória da oposição não seria reversível. Naquele momento, a campanha de Lula pôde beneficiar-se da condição oposicionista, de um discurso de marketing eleitoral bem sucedido em eliminar as restrições e medos da população em eleger um ex-operário de origem esquerdista, e do patrimônio ético acumulado pelo partido de Lula, o PT, notabilizado pelo combate à corrupção ao longo de sua história. Os principais meios da oligopolizada comunicação de massas no Brasil assistiram ao processo todo sem combater a candidatura Lula. Em 2006, o quadro foi totalmente diferente: após as denúncias e investigações parlamentares sobre a corrupção do seio do governo chefiado pelo PT, aquele patrimônio ético ficou indisponível para a propaganda lulista e as principais empresas de comunicação travaram uma batalha para eleger a oposição, até os últimos dias de campanha, repercutindo fortemente escândalos que levaram a eleição para o segundo turno, no qual Lula sagrou-se vencedor (com mais votos que em 2002), em grande parte por conta da virada nacionalista de sua propaganda que colocou o problema da corrupção dentro do governo em segundo plano. O dado atípico de 2006, segundo a tese de LIMA (2007) e colaboradores, foi que os meios de comunicação de massa, tradicionais formadores da opinião pública, foram deixados de lado pelos eleitores, e pela primeira vez a posição dessas empresas ${ }^{8}$ de comunicação não prevaleceu nos resultados eleitorais. O governo Lula foi capaz de descolar a opinião pública brasileira dos seus antigos formadores de opinião.

Ao resumir os usos políticos da história e o caráter de retroalimentação que isso tem para o aprendizado histórico por parte da população, que condiciona o ensino de História na escola, podemos destacar duas linhas. A primeira refere-se ao fato de que as imagens referentes ao nacionalismo mobilizadas pela esquerda no poder são, com poucas releituras, oriundas das visões do mito das três raças e de campanhas como "O Petróleo é nosso" (anos 50), assim como do movimento trabalhista ligado à herança de Getúlio Vargas. Ao que parece, não há imagens de outro nacionalismo, à esquerda que possa ser mobilizado. Outro fator é que o caráter da cultura histórica que pode ser mobilizada indica uma fraca relação

\footnotetext{
${ }^{8}$ O posicionamento dessas empresas ficou visível, segundo os colaboradores da obra citada, pela ampla maioria de matérias negativas quanto a Lula, acompanhadas pelo predomínio de matérias positivas quanto ao candidato Alckmin. Prevaleceu ainda na grande mídia uma atitude de hostilidade quanto ao candidato Lula, que se traduziu em uma cobertura desequilibrada a favor da oposição. O fato é que, no Brasil, nenhum grande meio de comunicação toma partido publicamente, e, portanto, procuram impor à sua cobertura o tom de uma neutralidade que não se comprova na cobertura que promovem das eleições.
} 
com a história nacional canônica, que se restringe majoritariamente à esfera política. Boa parte da explicação disso está no fato de que essa história canônica tem na escola o seu habitat natural, e a escolarização básica no Brasil massificou-se apenas nos anos 1970 e universalizou-se apenas nos anos 1990. Some-se a isso o fato de que essa narrativa é masculina, branca, eurocentrada. A grande maioria da população humilde no Brasil é negra ou descende de africanos a ameríndios, e termina por não se ver representada nessa história. Sua aceitação - e mesmo o conhecimento de seus ícones e próceres - não tem largo alcance. A história que a campanha Lula mobiliza é uma história social que contorna a história nacional canônica brasileira.

Por fim, uma campanha política não surge com a intenção de educar, mas de convencer para uma determinada atitude política. Subsidiariamente educa, mesmo porque se assemelha à educação, quando procede a um trabalho com ideias e informações para produzir na clientela um determinado saber, que só se justifica ao ser usado para a vida. Essa é uma das chaves para a compreensão do processo de aprendizagem de história, que nem de longe se resume ao que se ensina na escola. Na interação entre essas esferas, é dominante a opinião de que as propostas dos partidos e coligações devem ser objeto de discussão na escola. Cumpre ampliar essa perspectiva para incluir o modo de produção das imagens, para maior transparência dos apelos publicitários desenvolvidos. Desse modo, a mobilização de impulsos, desejos e sentimentos pode ser traduzida e governada também pelo destinatário da mensagem, de modo que possa decidir com mais consciência se adere ou não, por exemplo, a um apelo nacionalista, uma manifestação de indignação ou uma comoção diante de determinados fatores. Evidentemente, não se trata de excluir da consciência histórica sua parcela afetiva e ficcional, mas colaborar para a maior autonomia possível do sujeito. 


\section{Referências}

BAPTISTELLA, Ester Cecilia Fernandes. A compreensão do conteúdo de um comercial televisivo na infância. Campinas, SP: Dissertação de Mestrado FE - Unicamp, 2001.

BARTHES, Roland. Societé, imagination, publicité. In: BARTHES, Roland. Oeuvres completes. Paris: Seuil, 1994. p. 507-517.

BELINTANE, Claudemir. A escola e a lan-house. São Paulo: Mimeo, 2006.

BERGMANN, Klaus. A história na reflexão didática. São Paulo. Revista Brasileira de História, v.9, n. 19, p. 29 - 42, set. 89/fev. 90.

BURTON, Graeme. Talking television: an introduction to the study of television. London: Hodder Arnold H\&S, 2000.

CERRI, Luis, Fernando. 1972: Sete bandeiras do setecentenário por mil cruzeiros velhos. Estudos Ibero-Americanos. , v.XXV, p.193 - 208, 1999.

CERRI, Luis, Fernando. Didacticas publicas de la Historia: demandas sociais, políticas de Estado e usos da História no Brasil contemporâneo. In: Actas de las $X^{a s}$ Jornadas Interescuelas Departamentos de Historia. Rosario, Argentina: Escuela de Historia Universidad Nacional de Rosario, 2005.

CERRI, Luis, Fernando. Usos públicos da história no Brasil contemporâneo: demandas sociais e políticas de Estado. Araucaria, Sevilha, Espanha, v. 8, n. 15, p. 1-15, 2006.

DA MATTA, Roberto. Carnavais, malandros e heróis: para uma sociologia do dilema brasileiro. Rio de Janeiro: Rocco, 1997.

FERNANDES, Florestan. O negro no mundo dos brancos. São Paulo: DIFEL, 1971.

FUENZALIDA, Valerio. La política resignificada desde la televisión. Diálogo Político. Buenos Aires, v. 4, n. 1, p. 47 - 66, 2004.

FICO, Carlos. Reinventando o Otimismo: ditadura, propaganda e imaginário social no Brasil. Rio de Janeiro: Fundação Getúlio Vargas, 1997.

LAVILLE, Christian. Historical consciousness and Historical Education: what to Expect from the First to the Second. In: SEIXAS, Peter (ed.). Theorizing Historical Consciousness. Toronto: University of Toronto Press, 2004, p. 165 - 182.

LIMA, Venício Artur de. A mídia nas eleições de 2006. São Paulo: Fundação Perseu Abramo, 2007.

ORTIZ, Renato. Cultura Brasileira e Identidade Nacional. São Paulo: Brasiliense, 1985.

RAMALDES, Dalva; REIS, Ruth. Discursos e deslocamentos de Lula: estratégias da propaganda eleitoral da eleição à reeleição. In: CONGRESSO ANUAL DA ASSOCIAÇÃO BRASILEIRA DE PESQUISADORES DE COMUNICAÇÃO E POLÍTICA, 1, 2006, 
Salvador, BA. Anais eletrônicos... Belo Horizonte: UFMG. Disponível em:

$<$ http://www.fafich.ufmg.br/compolitica/anais2006/Ramaldes_e_Reis_2006.pdf>. Acesso em: 28 set. 2010.

RUBIM, A. A. C. Cultura e política na eleição de 2002: As estratégias de Lula presidente. Brasília: Mimeo, 2003. Disponível em: <http://egroups.unb.br/fac/comunicacaoepolitica/Albino.pdf>. Acesso em: 20 set. 2010.

RÜSEN, J. What is Historical Consciousness? - A Theoretical Approach to Empirical Evidence. In: CANADIAN HISTORICAL CONSCIOUSNESS IN AN INTERNATIONAL CONTEXT: THEORETICAL FRAMEWORKS, 2001, Vancouver. Paper... Vancouver: University of British Columbia, 2001.

WEST, D. M. Television Advertising in Election Campaigns. Political Science Quarterly. V. 109, [New York], n. 5. pp. 789-809, 1994-1995. 